\title{
Can a central blood volume deficit be detected by systolic pressure variation during spontaneous breathing?
}

\author{
Michael Dahl ${ }^{1 *}$, Chris Hayes ${ }^{1}$, Bodil Steen Rasmussen ${ }^{1}$, Anders Larsson ${ }^{2}$ and Niels H. Secher ${ }^{3}$
}

\begin{abstract}
Background: Whether during spontaneous breathing arterial pressure variations (APV) can detect a volume deficit is not established. We hypothesized that amplification of intra-thoracic pressure oscillations by breathing through resistors would enhance APV to allow identification of a reduced cardiac output (CO). This study tested that hypothesis in healthy volunteers exposed to central hypovolemia by head-up tilt.

Methods: Thirteen healthy volunteers were exposed to central hypovolemia by $45^{\circ}$ head-up tilt while breathing through a facemask with $7.5 \mathrm{cmH}_{2} \mathrm{O}$ inspiratory and/or expiratory resistors. A brachial arterial catheter was used to measure blood pressure and thus systolic pressure variation (SPV), pulse pressure variation and stroke volume variation. Pulse contour analysis determined stroke volume (SV) and CO and we evaluated whether APV could detect a $10 \%$ decrease in CO.
\end{abstract}

Results: During head-up tilt SV decreased form $91( \pm 46)$ to $55( \pm 24) \mathrm{mL}$ (mean \pm SD) and CO from $5.8( \pm 2.9)$ to 4.0 $( \pm 1.8) \mathrm{L} / \mathrm{min}(p<0.05)$, while heart rate increased $(65( \pm 11)$ to $75( \pm 13) \mathrm{bpm} ; P<0.05)$. Systolic pressure decreased from $127( \pm 14)$ to $121( \pm 13) \mathrm{mmHg}$ during head-up tilt, while SPV tended to increase (from $21( \pm 15) \%$ to $30( \pm 13)$ $\%$ ). Yet during head-up tilt, a SPV $\geq 37 \%$ predicted a decrease in $C O \geq 10 \%$ with a sensitivity and specificity of $78 \%$ and $100 \%$, respectively.

Conclusion: In spontaneously breathing healthy volunteers combined inspiratory and expiratory resistors enhance SPV during head-up tilted induced central hypovolemia and allow identifying a $10 \%$ reduction in CO. Applying inspiratory and expiratory resistors might detect a fluid deficit in spontaneously breathing patients.

Trial registration: ClinicalTrials.gov number NCT02549482 Registered September $10^{\text {th }} 2015$.

Keywords: Fluid responsiveness, Spontaneous breathing, Head-up tilt, Pulse pressure variation, Stroke volume variation, Systolic pressure variation

\section{Key messages}

In spontaneous breathing healthy volunteers combined inspiratory and expiratory resistors enhance systolic pressure variation and allow for identifying a central volume deficit with a sensitivity and specificity of $78 \%$ and $100 \%$, respectively. Combined inspiratory and expiratory resistors might help detecting a fluid deficit in spontaneously breathing patients.

\footnotetext{
* Correspondence: mida@rn.dk

${ }^{1}$ Department of Anesthesiology and Intensive Care Medicine, Aalborg

University Hospital, Hobrovej 18-21, DK-9000 Aalborg, Denmark

Full list of author information is available at the end of the article
}

\section{Background}

Fluid therapy is an integrated part of emergency and critical care medicine as in anesthesia. However, there are few measurements that asses hypovolemia and consequently to what extent a patient is in need of fluid, i.e. responds with improved cardiovascular function after volume administration (being "fluid responsive") [1]. Unfortunately, clinical judgment or, e.g. recording of central venous pressure [2-7] does not provide adequate information whether a patient is in need of intravascular volume expansion. In mechanically ventilated patients without cardiac arrhythmias exposed to a tidal volume larger than $8 \mathrm{~mL} / \mathrm{kg}$ lean body weight, arterial pressure 
variation (APV) predicts volume responsiveness defined as an increase in stroke volume (SV) or cardiac output (CO) when the patient is exposed to an intravascular volume load [8-14]. In spontaneously breathing patients however, APV is insufficient to guide volume therapy [15-17] and thus volume therapy is guided by recording of SV and/or $\mathrm{CO}$ response or change in end-tidal $\mathrm{CO}_{2}$ tension , e.g. when the patient is exposed to passive raising the legs $[16,18-20]$ or Trendelenburg's position [21]. Noteworthy, Zaniboni et al. [22] found a correlation for APV between mechanically ventilated patients and patients ventilated by spontaneous flow triggered synchronized intermittent mechanical ventilation.

Yet, APV can detect fluid responsiveness as demonstrated in swine breathing through an inspiratory and expiratory resistor that augment pulse pressure variations (PPV) [23] and in healthy volunteers with paced breathing and/or respiratory resistors [24]. Similarly, we considered whether the intra-thoracic pressure oscillations when amplified by inspiratory (increasing the negative intra-thoracic pressure) and expiratory resistors (increasing the expiratory intra-thoracic pressure) would allow detection of an intravascular volume deficit in humans. In this study, we tested that hypothesis in healthy humans exposed to a reduction in the central blood volume by head-up tilt. Separate evaluation was made by providing the subjects to an inspiratory resistance, to an expiratory resistance, or to both with no application of resistors serving as control. We aimed to identify which expression of APV is most sensitive to a significant reduction of the central blood volume resulting in a $10 \%$ reduction in $\mathrm{CO}$.

\section{Methods}

Thirteen healthy volunteers (four women) 25 years (range 18-36) of age (Table 1) were recruited through www.forsogsperson.dk. Exclusion criteria were pregnancy, breast-feeding or use of any medication. The protocol was approved by the ethics committee for human research for The Capital region of Denmark (H-4-2010-110) in accordance with the Helsinki II declaration and oral and written informed consent was obtained.

Table 1 Characteristics of the subjects $(n=13)$

\begin{tabular}{lc}
\hline Gender $(\mathrm{F} / \mathrm{M})$ & \multicolumn{1}{c}{$4 / 9$} \\
\hline Age $($ years $)$ & $25 \pm 5$ \\
Height $(\mathrm{cm})$ & $178 \pm 10$ \\
Weight $(\mathrm{kg})$ & $73 \pm 13$ \\
BMI $\left(\mathrm{kg} / \mathrm{m}^{2}\right)$ & $23.0 \pm 3.2$ \\
BSA $\left(\mathrm{m}^{2}\right)$ & $1.9 \pm 0.2$ \\
\hline
\end{tabular}

Values are mean \pm standard deviation

$B M I$ body mass index, $B S A$ body surface area
The volunteers were placed supine on a tilt table with heart rate monitored by a three-lead ECG and arterial oxygen saturation by pulse oximetry $\left(\mathrm{SpO}_{2}\right)$ (Philips SpO2 Sensor M1191BL ViCare Medical, Denmark) on the right third finger of the dominant hand. A peripheral venous access was established and a $20 \mathrm{G}$ arterial catheter was placed in the brachial artery of the nondominant arm and both were maintained by infusion of isotonic saline $(3 \mathrm{~mL} / \mathrm{h})$. The arterial catheter was connected to a transducer kept at heart level for registration of arterial pressure and stroke volume variation (SVV) (Vigileo-Flotrac $^{\mathrm{Tw}}$, version 1.07, Edwards Lifesciences, Nyon, Switzerland) as well as blood gas variables (ABL, Radiometer, Copenhagen). $\mathrm{CO}$ and the arterial pressure curve were stored for subsequent determination of arterial pulse pressure (PPV) and systolic pressure variation (SPV). Finally, a catheter was placed via a brachial vein and advanced to the subclavian vein to register central venous oxygen saturation $\left(\mathrm{ScvO}_{2}\right)(\mathrm{ABL}$, Radiometer, Copenhagen).

The subjects were breathing spontaneously with respiratory rate determined by capnography (Philips $\mathrm{CO}_{2}$ Filterline, ViCare Medical, Denmark) and provided with a facemask (Intersurgical Ltd., Wokingham, Berkshire, UK) (Fig. 1) randomly fitted with an inspiratory resistor, an expiratory resistor, a combination of the two resistors, or with no resistors. Each resistor provided a $7.5 \mathrm{cmH}_{2} \mathrm{O}$ threshold resistance (CPAP; Philips Respironics, Herrshing, Germany) and were applied for two minutes [18] with variables obtained in the second minute.

Initially, variables were recorded with each resistor configuration while the subjects were supine (normovolemia). Secondly, the table was tilted $45^{\circ}$ head-up to reduce the central blood volume hence simulating hypovolemia [25] (Fig. 2). Finally, $20^{\circ}$ head-down tilt was used to expand the central blood volume and hence simulating mild

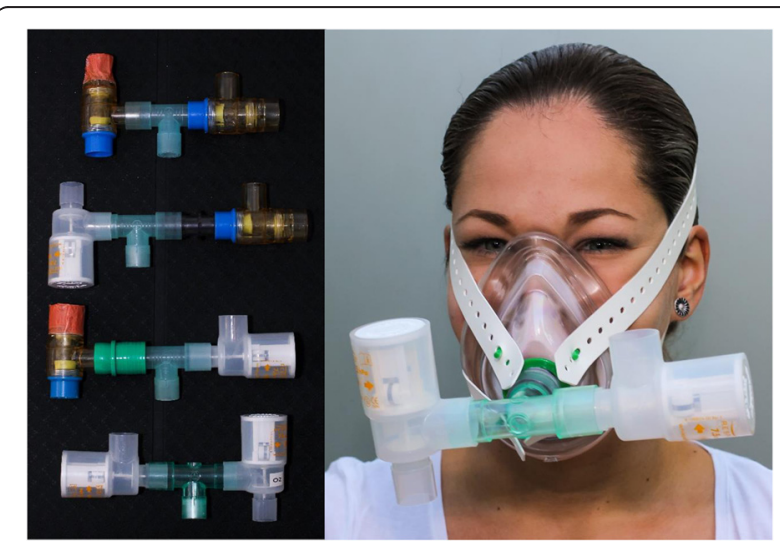

Fig. 1 Left: four respiratory resistors: no resistance, expiratory resistance, inspiratory resistance, and both inspiratory and expiratory resistances. Right: facemask applied with combined inspiratory and expiratory resistors (Model photo) 


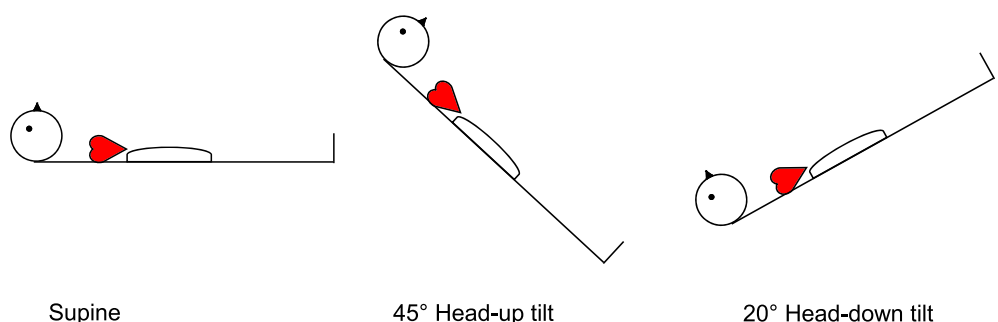

Fig. 2 Three postures representing normovolemia (supine), central hypovolemia (head-up tilt), and central hypervolemia (head-down tilt)

hypervolemia $[25,26]$. After each change of the tilt table position we allowed a 10 min equilibration time before variables were obtained.

$\mathrm{PPV}$ was $\left(\left(\mathrm{PP}_{\max }-\mathrm{PP}_{\min }\right) /\left(\left(\mathrm{PP}_{\max }+\mathrm{PP}_{\min }\right) / 2\right)\right) \times 100$, where $\mathrm{PP}_{\max }$ and $\mathrm{PP}_{\text {min }}$ are the maximal and minimal difference between systolic and diastolic pressure during the respiratory cycle, respectively [12] and SPV was calculated by an analogous formula. PPV and SPV were calculated from the stored recordings, while other variables were noted on-line.

\section{Statistics}

For a 1-beta (power) of 0.8 and an alpha $(P)$ of 0.05 and assuming an increase in arterial pressure variations by $10 \%$ with a SD of $5 \%$ by the intervention, a minimum of 8 subjects were needed. Statistics was performed with Stata 13.0 (StataCorp LP, Texas, USA) and QQ-plots identified that the data were normally distributed. Hemodynamic and respiratory responses were analyzed by using a two-way ANOVA with interaction between position and resistor. Estimation of fluid responsiveness

Table 2 Hemodynamic and respiratory variables at three postures whatever respiratory resistor(s) applied

\begin{tabular}{|c|c|c|c|}
\hline & Supine position & Head-up tilt & Head-down tilt \\
\hline Cardiac output (L/min) & $5.8 \pm 2.9$ & $4.0 \pm 1.8^{*}$ & $5.1 \pm 2.2^{*}$ \\
\hline Stroke Volume (mL) & $91 \pm 46$ & $55 \pm 24^{*}$ & $81 \pm 36^{*}$ \\
\hline $\begin{array}{l}\text { Systolic blood } \\
\text { pressure (mmHg) }\end{array}$ & $127 \pm 14$ & $121 \pm 13^{*}$ & $120 \pm 11^{*}$ \\
\hline $\begin{array}{l}\text { Diastolic blood } \\
\text { pressure (mmHg) }\end{array}$ & $64 \pm 7$ & $69 \pm 6^{*}$ & $65 \pm 6$ \\
\hline Heart rate $\left(\mathrm{min}^{-1}\right)$ & $65 \pm 11$ & $75 \pm 13^{*}$ & $65 \pm 11$ \\
\hline Respiratory rate $\left(\mathrm{min}^{-1}\right)$ & $10 \pm 4$ & $10 \pm 4$ & $10 \pm 3$ \\
\hline $\begin{array}{l}\text { Central venous } \\
\text { oxygen saturation }\end{array}$ & $0.79 \pm 0.07$ & $0.68 \pm 0.13$ & $0.79 \pm 0.09$ \\
\hline $\mathrm{Ph}$ & $7.43 \pm 0.03$ & $7.45 \pm 0.04^{*}$ & $7.44 \pm 0.04$ \\
\hline $\begin{array}{l}\text { Oxygen partial } \\
\text { pressure (kPa) }\end{array}$ & $14.1 \pm 1.6$ & $14.3 \pm 1.0$ & $14.7 \pm 1.6^{*}$ \\
\hline $\begin{array}{l}\text { Carbondioxid partial } \\
\text { pressure }(\mathrm{kPa})\end{array}$ & $5.0 \pm 0.6$ & $4.6 \pm 0.7^{*}$ & $4.8 \pm 0.7^{*}$ \\
\hline
\end{tabular}

Values are mean \pm standard deviation. ${ }^{*} P<0.05$ compared to the supine position

There was no interaction between position and application of resistors was carried out using an ANOVA model with resistor as factor, only for head-up tilt, and Receiver Operating Characteristic (ROC) (Hanley and McNeil's method). A $P$ value $<0.05$ was considered statistically significant.

\section{Results}

Hemodynamic responses and blood gas variables

From the supine position to head-up tilt $\mathrm{CO}$ decreased from $5.8( \pm 2.9)$ to $4.0( \pm 1.8) \mathrm{L} / \mathrm{min}$ (mean $\pm \mathrm{SD})$, SV from $91( \pm 46)$ to $55( \pm 24) \mathrm{ml}$, systolic pressure from $127( \pm 14)$ to $121( \pm 13) \mathrm{mmHg}$ and $\mathrm{ScvO}_{2}$ from $0.79( \pm 0.07) \%$ to $0.68( \pm 0.13) \%$, while diastolic pressure $(64, \pm 7)$ to $69( \pm 6)$ $\mathrm{mmHg})$ and heart rate $(65( \pm 11)$ to $75( \pm 13) \mathrm{bpm})$ increased $(P<0.05)$. Similarly, from the supine position to head-down tilt there was a decrease in $\mathrm{CO}, \mathrm{SV}$ and systolic pressure but no changes in heart rate, diastolic pressure or $\mathrm{ScrO}_{2}$ (Table 2). There were no changes in respiratory rate or $\mathrm{SpO}_{2}$ between the three body positions and only small changes in arterial blood gas variables and no significant interactions between position and respiratory resistor application.

\section{Detecting central hypovolemia}

Ten volunteers showed $\mathrm{a} \geq 10 \%$ decrease in CO between the supine and head-up tilt positions. Regardless of tilt table position the combined inspiratory and expiratory resistors increased SVV, SPV and PPV, while the inspiratory resistor increased SPV and PPV and the expiratory resistor only SPV (Table 3). Sensitivity, specificity, positive predictive value, negative predictive value, area under the curve (AUC), and optimal cut-off for these

Table 3 Arterial pressure variations with different airway resistors during head-up tilt

\begin{tabular}{lcccc}
\hline & No resistor (\%) & $\begin{array}{l}\text { Inspiratory } \\
\text { resistor (\%) }\end{array}$ & $\begin{array}{l}\text { Expiratory } \\
\text { resistor (\%) }\end{array}$ & $\begin{array}{l}\text { Inspiratory/ } \\
\text { expiratory } \\
\text { resistor (\%) }\end{array}$ \\
\hline $\begin{array}{l}\text { Systolic pressure } \\
\text { variation }\end{array}$ & $17 \pm 11$ & $26 \pm 14^{*}$ & $26 \pm 18^{*}$ & $28 \pm 14^{*}$ \\
$\begin{array}{l}\text { Stroke volume } \\
\text { variation }\end{array}$ & $15 \pm 8$ & $19 \pm 8$ & $23 \pm 7^{*}$ & $29 \pm 12^{*}$ \\
$\begin{array}{l}\text { Pulse pressure } \\
\text { variation }\end{array}$ & $7 \pm 4$ & $9 \pm 6$ & $8 \pm 6$ & $10 \pm 6^{*}$ \\
\hline $\begin{array}{l}\text { Values are mean } \\
\text { Salandard deviation }\end{array}$ & & & & \\
\hline
\end{tabular}

Values are mean \pm standard deviation. ${ }^{*} P<0.05$ compared to no resistor 
Table 4 Sensitivity, specificity, positive predictive value and negative predictive value using $10 \%$ difference in cardiac output between supine position to head-up tilt to define central hypovolemia

\begin{tabular}{|c|c|c|c|c|c|c|}
\hline & AUC & Optimal cut-off (\%) & Sensitivity (\%) & Specificity (\%) & $\begin{array}{l}\text { Positive predictive } \\
\text { value (\%) }\end{array}$ & $\begin{array}{l}\text { Negative predictive } \\
\text { value (\%) }\end{array}$ \\
\hline \multicolumn{7}{|l|}{ Stroke volume variation } \\
\hline No resistor & $0.73(0.46 ; 1.00)$ & 13 & 60 & 100 & 100 & 43 \\
\hline Expiratory resistor & $0.82(0.58 ; 1.00)$ & 28 & 70 & 100 & 100 & 50 \\
\hline Inspiratory resistor & $0.75(0.46 ; 1.00)$ & 18 & 50 & 100 & 100 & 38 \\
\hline Ins-/expiratory resistor & $0.58(0.28 ; 0.88)$ & 31 & 40 & 100 & 100 & 33 \\
\hline \multicolumn{7}{|l|}{ Systolic pressure variation } \\
\hline No resistor & $0.43(0.10 ; 0.77)$ & 19 & 20 & 100 & 100 & 27 \\
\hline Expiratory resistor & $0.70(0.37 ; 1.00)$ & 33 & 70 & 67 & 88 & 40 \\
\hline Inspiratory resistor & $0.67(0.25 ; 1.00)$ & 36 & 80 & 67 & 89 & 50 \\
\hline Ins-/expiratory resistor & $0.96(0.86 ; 1.00)$ & 37 & 78 & 100 & 100 & 60 \\
\hline \multicolumn{7}{|l|}{ Pulse pressure variation } \\
\hline No resistor & $0.83(0.61 ; 1.00)$ & 7 & 80 & 100 & 100 & 60 \\
\hline Expiratory resistor & $0.73(0.40 ; 1.00)$ & 4 & 70 & 67 & 88 & 40 \\
\hline Inspiratory resistor & $0.73(0.42 ; 1.00)$ & 7 & 50 & 100 & 100 & 38 \\
\hline Ins-expiratory resistor & $0.59(0.25 ; 0.93)$ & 12 & 67 & 67 & 86 & 40 \\
\hline \multicolumn{7}{|c|}{ Central venous oxygen saturation } \\
\hline No resistor & $0.67(0.29 ; 1.00)$ & 71 & 50 & 100 & 100 & 40 \\
\hline Expiratory resistor & $0.46(0.02 ; 0.90)$ & 70 & 50 & 50 & 75 & 25 \\
\hline Inspiratory resistor & $0.42(0.00 ; 0.88)$ & 77 & 50 & 50 & 75 & 25 \\
\hline Ins-expiratory resistor & $0.50(0.08 ; 0.92)$ & 77 & 33 & 100 & 100 & 33 \\
\hline
\end{tabular}

AUC area under the curve with confidence interval
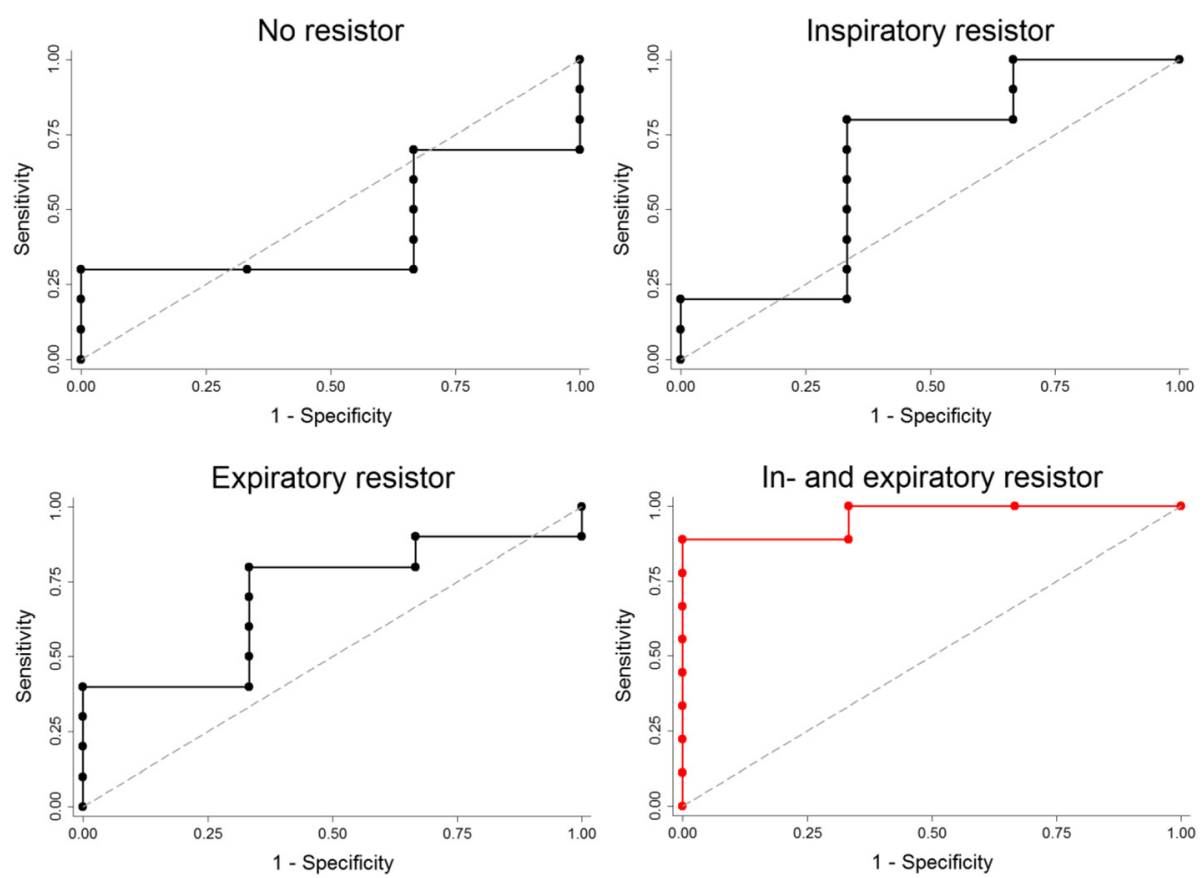

Fig. 3 Receiver operating characteristic (ROC) curves during head-up tilt for systolic pressure variation (SPV) with the four different respiratory resistors. Area under the ROC curve $0.43(0.10 ; 0.77$ ) (confidence interval) for no resistor, $0.67(0.25 ; 1.00)$ for the inspiratory resistor, 0.70 (0.37; 1.00$)$ for the expiratory resistor, and $0.96(0.86 ; 1.00)$ for the combined inspiratory and expiratory resistor 


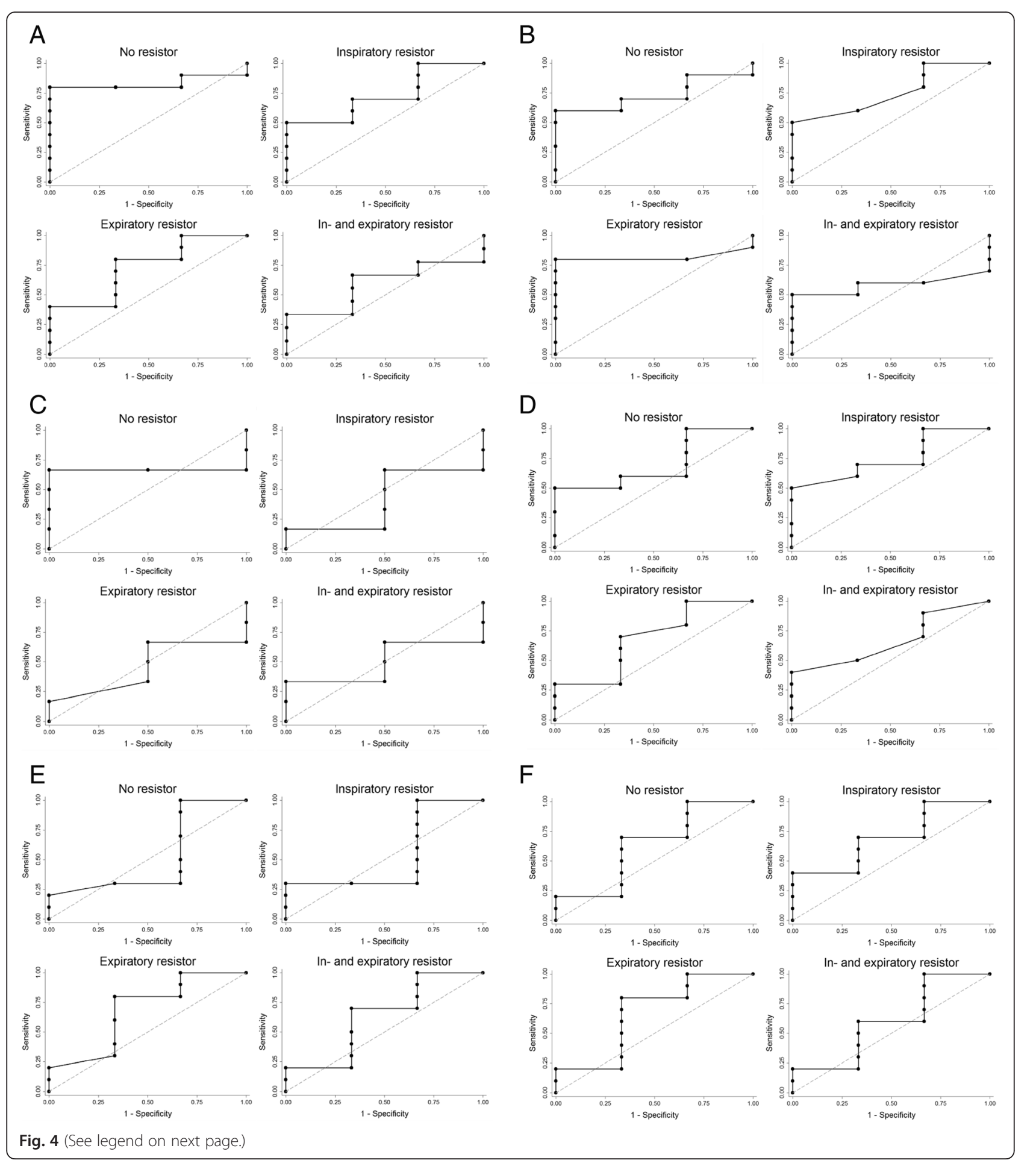




\section{(See figure on previous page.)}

Fig. 4 Receiver operating characteristic (ROC) curves during head-up tilt with the four different respiratory resistors. a: Pulse pressure variation (PPV) with area under the ROC curve $0.83(0.61 ; 1.00)$ (confidence interval) for no resistor, $0.73(0.42 ; 1.00)$ for the inspiratory resistor, $0.73(0.40 ; 1.00)$ for the expiratory resistor, and $0.59(0.25 ; 0.93)$ for the combined inspiratory and expiratory resistor. $\mathbf{b}$ : Stroke volume variation (SW) with area under the ROC curve $0.73(0.46 ; 1.00)$ for no resistor, $0.75(0.46 ; 1.00)$ for the inspiratory resistor, $0.82(0.58 ; 1.00)$ for the expiratory resistor, and 0.58 $(0.28 ; 0.88)$ for the combined inspiratory and expiratory resistor. c: Central venous oxygen saturation $\left(\mathrm{ScvO}_{2}\right)$ with area under the $\mathrm{ROC}$ curve 0.67 $(0.29 ; 1.00)$ for no resistor, $0.42(0.00 ; 0.88)$ for the inspiratory resistor, $0.46(0.02 ; 0.90)$ for the expiratory resistor, and $0.50(0.08 ; 0.92)$ for the combined inspiratory and expiratory resistor. $\mathbf{d}$ : Systolic blood pressure with area under the ROC curve $0.70(0.37 ; 1.00)$ for no resistor, $0.75(0.46 ; 1.00)$ for the inspiratory resistor, $0.68(0.31 ; 1.00)$ for the expiratory resistor, and $0.67(0.34 ; 0.99)$ for the combined inspiratory and expiratory resistor. e: Heart rate (HR) with area under the ROC curve $0.52(0.08 ; 0.95)$ for no resistor, $0.53(0.11 ; 0.96)$ for the inspiratory resistor, $0.68(0.29 ; 1.00)$ for the expiratory resistor, and $0.63(0.22 ; 1.00)$ for the combined inspiratory and expiratory resistor. f: Stroke volume (SV) with area under the ROC curve $0.63(0.22 ; 1.00)$ for no resistor, $0.70(0.36 ; 1.00)$ for the inspiratory resistor, $0.67(0.25 ; 1.00)$ for the expiratory resistor, and $0.60(0.19 ; 1.00)$ for the combined inspiratory and expiratory resistor

variables, as well as $\mathrm{ScvO}_{2}$ are shown in Table 4. The best prediction of a central volume deficit (a $10 \%$ reduction in $\mathrm{CO}$ ) was obtained with SPV when the combined resistors were applied. For that configuration SPV tended to increase (from $21( \pm 15) \%$ to $30( \pm 13) \%)$ and revealed a sensitivity of $78 \%$ and a specificity of $100 \%$ with a positive predictive value of $100 \%$, a negative predictive value of $60 \%$, and an AUC of $0.96(0.86 ; 1.00)$ (confidence interval) (Fig. 3) when SPV was larger than $37 \%$. Figure 4, Panels a-f show ROC-curves for PPV, $\mathrm{SVV}, \mathrm{ScvO}_{2}$, systolic blood pressure, heart rate and SV for comparison.

\section{Discussion}

In spontaneously breathing healthy volunteers application of a $7.5 \mathrm{cmH}_{2} \mathrm{O}$ threshold resistance on both the inspiratory and expiratory side of a facemask during head-up tilt induced central hypovolemia enhanced the variation in arterial pressure during the respiratory cycle sufficiently to detect a $10 \%$ reduction in CO. The highest sensitivity $(78 \%)$ and specificity (100\%) was observed for SPV with a threshold of $37 \%$. As a proof of principle, the results are in line with results by Bronzwaer et al. [24]. However, in contrast to the present findings that group found PPV to be superior to SPV. This difference may be due to a lower breathing rate in the Bronzwaer-study and hence larger tidal volume as well as blood pressure measurement by the non-invasive volume clamp method. Furthermore, we did not find any of the more commonly used variables, e.g. $\mathrm{ScvO}_{2}, \mathrm{SV}$, heart rate or systolic blood pressure to be superior to SPV when the combined inspiratory and expiratory resistor was applied (Fig. 4, Panel a-f).

Head-up tilt $[25,27]$ as, e.g. lower body negative pressure, eventually combined with heat stress [28] reduces the central blood volume and has the advantage compared to a blood loss that the intervention can be terminated immediately if the subject becomes ill. That central hypovolemia was provoked by head-up tilt was indicated by a decrease in $\mathrm{ScvO}_{2}$ and an increase in heart rate [29]. We found $\mathrm{CO}$ and $\mathrm{SV}$ also to decrease during head-down tilt, however the reduction was so small that it did not affect $\mathrm{ScrO}_{2}$ significantly and neither Harms et al. [29] nor Bundgaard-Nielsen et al. [30] found a decrease in $\mathrm{CO}$ during head-down tilt and only a decrease in SV when the subjects were tilted $90^{\circ}$ headdown. Similarly, moderate head-down tilt did not affect heart rate significantly $[29,30]$. Variables were obtained after a ten-minute equilibration period in each body position with randomized application of the resistors. A shorter equilibration period, e.g. one minute, is probably enough to register pulse changes during tilt tests [27], but we decided to use a longer period to be sure that the central blood volume was displaced.

Our study has several limitations: First, we studied healthy volunteers who may not be representative for a hospitalized population. For example, in an ICU population only $50 \%$ of patients increase $\mathrm{CO} \geq 10 \%$ when challenged with a fluid bolus [31]. Furthermore, the subjects were not fasting or told to abstain from heavy physical exercise and caffeinated beverages prior to the experiment. Secondly, our test was "the reverse" of the clinical practice; i.e. we provoked central hypovolemia by tilting the subjects headup and evaluated the change in $\mathrm{CO}$ and arterial pressure variations, and did not study whether these changes would be corrected by fluid administration. The $\mathrm{CO}$ decreased by more than $10 \%$ in 10 of 13 subjects when exposed to $45^{\circ}$ head-up tilt and a larger tilt angle would likely result in a more significant reduction of $\mathrm{CO}$. However, we used a relatively long equilibration period. Thirdly, we used an uncalibrated pulse contour technic to detect SV and CO [32]. Fourthly, the results depend not only on the resistance of the resistors, but also on the respiratory effort by the subjects. The threshold resistance was set at $7.5 \mathrm{cmH}_{2} \mathrm{O}$ and chosen because that level is in accordance with an animal study using SPV to indicate hypovolemia [23]. An airway threshold resistor between 5 and $10 \mathrm{cmH}_{2} \mathrm{O}$ is used for positive end-expiratory pressure or continuous positive airway pressure and is accepted by most patients. Finally, we did not control the breathing rate. A fixed slow paced breathing might have enhanced the results as demonstrated by Zöllei et al. [33] and Bronzwaer et al. [24]. 


\section{Conclusion}

Applying inspiratory and expiratory resistors to spontaneously breathing healthy volunteers allows for identifying significant central hypovolemia by recording of systolic pressure variations.

The clinical implication of the results is that systolic pressure variations might be used to detect a volume deficit in spontaneously breathing patients.

\section{Abbreviations}

APV, arterial pressure variation; CO, cardiac output; CVP, central venous pressure; $P P_{\text {max }}$ maximal pulse pressure; $\mathrm{PP}_{\min }$, minimal pulse pressure; $\mathrm{PPV}$, pulse pressure variation; $\mathrm{SCVO}_{2}$, central venous oxygen saturation; SPV, systolic pressure variation; SV, stroke volume; SW, stroke volume variation

\section{Acknowledgements}

María Rodrigo, MSc, statistician, Aalborg University Hospital for help, Finn Vestergaard, MD, Aalborg University Hospital for English proofreading and Tina Hellevik, LPN, Aalborg University Hospital for Fig. 1.

\section{Funding}

Anders Larsson is supported by grants from the Swedish Heart and Lung foundation and from the Swedish Research Council (K2015-99X-22731-01-4). Furthermore, we thank the Laerdal Foundation for Acute Medicine for financial support.

\section{Availability of data and materials}

Data and materials are available by contacting the author.

\section{Authors' contribution}

MD and NHS participated in the design, laboratory work, data analysis and writing the manuscript. $\mathrm{AL}, \mathrm{CH}$ and BSR participated in the design, data analysis and in finalizing the manuscript.

\section{Competing interests}

The authors declare that they have no competing Intresets.

\section{Consent for publication}

Associated with Fig. 1 the pictured person has provided written consent for publication.

\section{Ethics approval and consent to participate}

The protocol was approved by the ethics committee for human research for The Capital region of Denmark (H-4-2010-110) in accordance with the Helsinki II declaration and oral and written informed consent was obtained.

\section{Author details}

${ }^{1}$ Department of Anesthesiology and Intensive Care Medicine, Aalborg University Hospital, Hobrovej 18-21, DK-9000 Aalborg, Denmark ${ }^{2}$ Hedenstierna laboratory, Section of Anesthesiology and Intensive Care, Department of Surgical Sciences, Uppsala University, ANIVA Ing. 70, 1. tv., S-75643 Uppsala, Sweden. ${ }^{3}$ Department of Anesthesiology, The Copenhagen Muscle Research Center Rigshospitalet 2043, University of Copenhagen, Blegdamsvej 9, DK-2100 Copenhagen, Denmark.

Received: 21 November 2015 Accepted: 14 July 2016

Published online: 11 August 2016

References

1. Rooke G, Schwid H, Shapira Y. The Effect of Graded Hemorrhage and Intravascular Volume Replacement on Systolic Pressure Variation in Humans During Mecanical and Spontaneous Ventilation. Anesth Analg. 1995;80:925-32.

2. Berlin DA, Bakker J. Starling curves and central venous pressure. Crit Care. 2015;19:55-61

3. Cecconi M, Hofer C, Teboul J-L, Pettila V, Wilkman E, Molnar Z, Della Rocca G, Aldecoa C, Artigas A, Jog S, Sander M, Spies C, Lefrant J-Y, De Backer D. Fluid challenges in intensive care: the FENICE study. Intensive Care Med. 2015:41:1529-37.
4. Marik PE, Cavallazzi R. Does the Central Venous Pressure Predict Fluid Responsiveness? An Updated Meta-Analysis and a Plea for Some Common Sense. Crit Care Med. 2013;41:1774-81.

5. Secher NH, Van Lieshout JJ. Hypovolaemic Shock. In: Clinical Fluid Therapy in the Perioperative Setting. London, United Kingdom: Cambridge University Press. 2011:166-176.

6. Wu Y, Zhou S, Zhou Z, Liu B. A 10 second fluid challenge guided by transthoracic echocardiography can predict fluid responsiveness. Crit Care. 2014;18:R108.

7. De Backer D, Scolletta S. Why do pulse pressure variations fail to predict the response to fluids in acute respiratory distress syndrome patients ventilated with low tidal volume? Crit Care. 2011;15:150.

8. Cecconi M, Monge García MI, Gracia Romero M, Mellinghoff J, Caliandro F, Grounds RM, Rhodes A. The Use of Pulse Pressure Variation and Stroke Volume Variation in Spontaneously Breathing Patients to Assess Dynamic Arterial Elastance and to Predict Arterial Pressure Response to Fluid Administration. Anesth Analg. 2015;120:76-84.

9. Feihl F, Broccard AF. Interactions between respiration and systemic hemodynamics. Part I: basic concepts. Intensive Care Med. 2009:35:45-54

10. Feihl F, Broccard AF. Interactions between respiration and systemic hemodynamics. Part II: practical implications in critical care. Intensive Care Med. 2009;35:198-205.

11. Magder S. Clinical usefulness of respiratory variations in arterial pressure. Am J Respir Crit Care Med. 2004;169:151-5.

12. Michard F, Chemla D, Richard C, Wysocki M, Pinsky MR, Lecarpentier Y, Teboul JL. Clinical use of respiratory changes in arterial pulse pressure to monitor the hemodynamic effects of PEEP. Am J Respir Crit Care Med. 1999:159:935-9.

13. Michard F, Teboul J. Predicting fluid responsiveness in ICU patients: A critical analysis of the evidence. Chest. 2002:121:2000-8.

14. Yang $X$, Du B. Does pulse pressure variation predict fluid responsiveness in critically ill patients? A systematic review and meta-analysis. Crit Care. 2014; 18:650

15. Heenen S, De Backer D, Vincent J-L. How can the response to volume expansion in patients with spontaneous respiratory movements be predicted? Crit Care. 2006:10:R102.

16. Teboul J-L, Monnet X. Prediction of volume responsiveness in critically ill patients with spontaneous breathing activity. Curr Opin Crit Care. 2008;14:334-9.

17. Soubrier S, Saulnier F, Hubert H, Delour P, Lenci H, Onimus T, Nseir S, Durocher A. Can dynamic indicators help the prediction of fluid responsiveness in spontaneously breathing critically ill patients? Intensive Care Med. 2007:33:1117-24.

18. Monnet X, Rienzo M, Osman D, Anguel N, Richard C, Pinsky MR, Teboul J-L. Passive leg raising predicts fluid responsiveness in the critically ill. Crit Care Med. 2006;34:1402-7.

19. Monnet X, Bataille A, Magalhaes E, Barrois J, Le Corre M, Gosset C, Guerin L, Richard C, Teboul J-L. End-tidal carbon dioxide is better than arteria pressure for predicting volume responsiveness by the passive leg raising test. Intensive Care Med. 2013;39:93-100.

20. Monnet $X$, Teboul J-L. Passive leg raising: five rules, not a drop of fluid! Crit Care. 2015;19:18

21. Frost $\mathrm{H}$, Mortensen $\mathrm{C}$, Secher $\mathrm{N}$, Nielsen $\mathrm{H}$. Postoperative volume balance: Does stroke volume increase in Trendelenburg's position. Clin Physiol Func Imag. 2015. (In press).

22. Zaniboni M, Formenti P, Umbrello M, Galimberti A, Noto A, lapichino G. Pulse and systolic pressure variation assessment in partially assisted ventilatory support. J Clin Monit Comput. 2008;22:355-9.

23. Dahl MK, Vistisen ST, Koefoed-Nielsen J, Larsson A. Using an expiratory resistor, arterial pulse pressure variations predict fluid responsiveness during spontaneous breathing: an experimental porcine study. Crit Care. 2009:13:R39.

24. Bronzwaer A-SGT, Ouweneel DM, Stok WJ, Westerhof BE, van Lieshout JJ. Arterial Pressure Variation as a Biomarker of Preload Dependency in Spontaneously Breathing Subjects - A Proof of Principle. PLoS One. 2015:10, e0137364.

25. Matzen S, Perko G, Groth S, Friedman DB, Secher NH. Blood volume distribution during head-up tilt induced central hypovolaemia in man. Clin Physiol. 1991;11:411-22.

26. Brigden W, Howarth S, Sharpey-Schafer EP. Postural changes in the peripheral blood-flow of normal subjects with observations on vasovagal 
fainting reactions as a result of tilting, the lordotic posture, pregnancy and spinal anæsthesia. Clin Sci. 1950;9:79-90.

27. Knopp R, Claypool R, Leonardi D. Use of the Tilt Test in Measuring Acute Blood Loss. Ann Emerg Med. 1980;9:29-32.

28. Wilson TE, Brothers RM, Tollund C, Dawson EA, Nissen P, Yoshiga CC, Jons C, Secher NH, Crandall CG. Effect of thermal stress on Frank-Starling relations in humans. J Physiol. 2009;587:3383-92.

29. Harms MPM, Van Lieshout JJ, Jenstrup M, Pott F, Secher NH. Postural effects on cardiac output and mixed venous oxygen saturation in human. Exp Physiol. 2003;88:611-6.

30. Bundgaard-Nielsen M, Sørensen H, Dalsgaard M, Rasmussen P, Secher NH. Relationship between stroke volume, cardiac output and filling of the heart during tilt. Acta Anaesthesiol Scand. 2009;53:1324-8.

31. Magder S. Predicting volume responsiveness in spontaneously breathing patients: still a challenging problem. Crit Care. 2006;10:165

32. Monnet X, Anguel N, Naudin B, Jabot J, Richard C, Teboul J-L. Arterial pressure-based cardiac output in septic patients: different accuracy of pulse contour and uncalibrated pressure waveform devices. Crit Care. 2010;14:R109.

33. Zöllei É, Bertalan V, Németh A, Csábi P, László I, Kaszaki J, Rudas L. Non-invasive detection of hypovolemia or fluid responsiveness in spontaneously breathing subjects. BMC Anesthesiol. 2013;13:40.

Submit your next manuscript to BioMed Central and we will help you at every step:

- We accept pre-submission inquiries

- Our selector tool helps you to find the most relevant journal

- We provide round the clock customer support

- Convenient online submission

- Thorough peer review

- Inclusion in PubMed and all major indexing services

- Maximum visibility for your research

Submit your manuscript at www.biomedcentral.com/submit
Biomed Central 